\title{
A Middle Aged Man Presented with Recurrent Hypokalaemia and Basal Ganglia Calcification
}

APARNA DAS, ${ }^{1}$ RABAB SULTANA, ${ }^{2}$ M.A. KAHHAR ${ }^{3}$

\section{Case summary}

A 44-year-old, Bangladeshi male, normotensive, non diabetic, presented withrecurrent episodes of muscle cramping and twitching during last 10 years especially of hands and facial muscles. It usually lasts for about 5-7 minutes but sometimes persist for several hours to 1 day. He becomes lethargic after each episode. He takes oral potassium and calcium containing food and supplements regularly. He need injectable potassium supplement occasionally. He denied any form of self-medication, surreptitious diuretic or laxative abuse, persistent vomiting and diarrhea.

He also had recurrent episodic of convulsion for last 10 years. It lasts for 10-15 minutes, generalized, tonic-clonic variety. He denied any association with aura, nausea, headache, postictal confusion or memory loss, urinary or fecal incontinence, tongue-bitingor rolling of eyes. These episodes aggravates during emotional excitement, stress or tension. His family

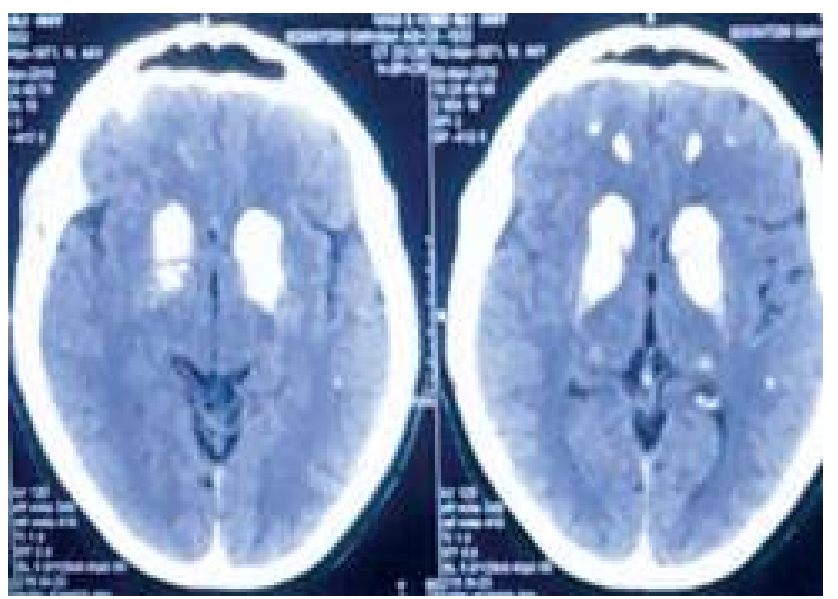

Fig - 1: CT scan of brain.

1. Assoc. Prof, Dept. of Medicine, Dhaka Medical College \& Hospital.

2. Dr. Rabab Sultana, Post graduate trainee, Dept. of Medicine, Dhaka Medical College \& Hospital.

3. Prof. Md. Azizul Kahhar, Professor, Dept. of Medicine, Dhaka Medical College \& Hospital.

Correspondence: Dr. Aparna Das, Assoc. Prof, Dept. of Medicine, Dhaka Medical College\& Hospital. Email: aparna_0191 @yahoo.com. history does not suggestive of such type of illness. On query he gave a history of taking large amount of drinking water (approx. 7.5 litres) and excessive micturition (approx.6.5 litres) everyday. First episode occurred in 2006. Then, he was admitted in hospital and was diagnosed as a case of electrolyte imbalance (Recurrent hypocalcaemia with hypokalemic periodic paralysis). On examination revealed fully oriented patient with no abnormality except Chvostek and Trousseau's signs were strongly positive during and twice after admission which resolved after giving Inj. Calcium gluconate and Inj. KT respectively. All systemic examinations including fundoscopy were normal. Laboratory investigation srevealed CT scan of Brain (Fig.-1) showing extensive symmetrical bilateral hyperdense (calcification) area seen in the basal ganglia, halamus and both cerebellar hemishere, deep white matter of fronto-parietal lobesconsistent with Fahr'sdisease.

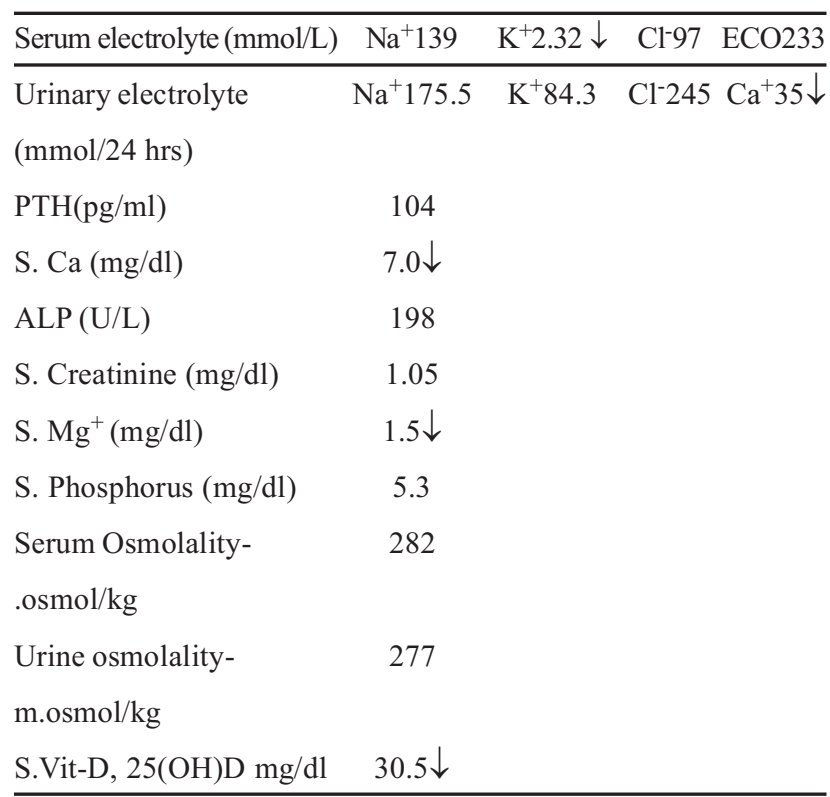

E.C.G. was normal probably as he was on supplemental therapy. X-ray of both hand joints were normal. USG of W/ A - both kidneys are slightly swollen with defined cortex and medulla - suggestive of pyelonephritis with cystitis. No calculi or cyst seen in either kidney. X-Ray KUB reveals radio opaque shadow, abnormal calcification or soft tissue 
swelling located in KUB region. Parathyroid scintigraphy: Scan is negative for parathyroid adenoma or hyperplasia. Fundal photograph was normal and calcification was not seen. Blood gas analysis revealed mild hypokalemic metabolic alkalosis with respiratory compensation. Water deprivation test was suggestive of psychogenic polydyspsia.

\section{Discussion:}

Gitelman syndrome is an inherited tubulopathy that must be considered in some settings of unexplained hypokalemia. It was first described by American physicians Hillel J. Gitelman (1932-2015), Greham, and Welt in 1966. It is caused due to loss of function mutation in SLC12A3 gene affecting thiazide sensitive sodium-chloride symporter located in distal convoluted tubule. This cell membrane participates in control of ion homeostasis at DCT of nephrons. ${ }^{1,2}$ Patients usually present during adolescence or even adulthood. The diagnosis can be made on the basis of clinical features, laboratory investigations, and renal function tests. Treatment usually aims to correct electrolyte imbalance. Here this gentleman presented tous with the typical symptoms along with very rare associations of late age onset, hypocalcemia, basalganglial calcification, periodic paralysis and Vit-D deficiency. Approx. $6 \%$ of patients of Gittelman present with hypokalemic periodic paralysis. ${ }^{3,4}$ Calcification is a very uncommon condition in Gitelman syndrome. There are a few case reports of Gitelman syndrome with sclerochoroidalcal cifications. In patients with hypophophastasia, a deficiency of tissue non-specific alkaline phosphatase allows an increase in extracellular inorganic pyrophosphate and thus CPPD (calcium pyrophosphate dehydrate) disease. Magnesium is a cofactor for alkaline phosphatase and hypomagnesaemia associated with Gitelman syndrome may thus theoretically reduce the activity of alkaline phosphatase and predispose to CPPD disease. ${ }^{4}$ Treatment is correction of electrolyte. Therefore, a high index of suspicion is needed to diagnose such case.The long-termprognosis is excellent.

\section{References:}

1. Field MJ, Burnett L, Sullivan DR, Stewart P. Clinical biochemistry and metabolism, Davidson principles and practice of Medicine, $22^{\text {nd }}$ edition, Elsevier: 441-442.

2. Cruz DN, Shaer AJ, Bia MJ, Lifton RP, Simon DB, Gitelman revisited, Kidney Int. 2001;59:710-7.

3. Gutierrez M, Silveri F, Bertolazzi C, Salaffi F, Giacchetti G, Girolimetti R. et al. Gitelman syndrome, calcium pyrophosphate dihydrate deposition disease and crowned dens syndrome. A new association? Rheumatology. 2010; 49(3):610-613.

4. Gupta R, Hu V, Reynolds T and Harrison R. Sclerochoroidal calcification associated with Gitelman syndrome and calcium pyrophosphate dihydrate deposition J Clin Pathol. 2005; 8(12): 1334-1335. 